\title{
Bay Leaf (Laurus Nobilis L.) Incense Improved Scopolamine-Induced Amnesic Rats by Restoring Cholinergic Dysfunction and Brain Antioxidant Status
}

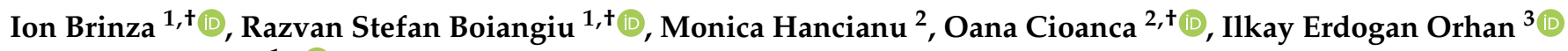 \\ and Lucian Hritcu ${ }^{1, *(D)}$ \\ 1 Department of Biology, Faculty of Biology, Alexandru Ioan Cuza University of Iasi, 700506 Iasi, Romania; \\ ion.brinza@student.uaic.ro (I.B.); razvan.boiangiu@student.uaic.ro (R.S.B.) \\ 2 Department of Pharmacognosy, Faculty of Pharmacy, Grigore T. Popa University of Medicine and Pharmacy Iasi, \\ 700115 Iasi, Romania; monica.hancianu@umfiasi.ro (M.H.); oana.cioanca@umfiasi.ro (O.C.) \\ 3 Department of Pharmacognosy, Faculty of Pharmacy, Gazi University, 06330 Ankara, Turkey; \\ iorhan@gazi.edu.tr \\ * Correspondence: hritcu@uaic.ro; Tel.: +40-232-201666 \\ + These authors contributed equally to this work.
}

check for updates

Citation: Brinza, I.; Boiangiu, R.S.; Hancianu, M.; Cioanca, O.; Erdogan Orhan, I.; Hritcu, L. Bay Leaf (Laurus Nobilis L.) Incense Improved

Scopolamine-Induced Amnesic Rats by Restoring Cholinergic Dysfunction and Brain Antioxidant Status. Antioxidants 2021, 10, 259. https:// doi.org/10.3390/antiox10020259

Academic Editor:

Christos Kontogiorgis

Received: 12 January 2021

Accepted: 1 February 2021

Published: 8 February 2021

Publisher's Note: MDPI stays neutral with regard to jurisdictional claims in published maps and institutional affiliations.

Copyright: (c) 2021 by the authors. Licensee MDPI, Basel, Switzerland. This article is an open access article distributed under the terms and conditions of the Creative Commons Attribution (CC BY) license (https:// creativecommons.org/licenses/by/ $4.0 /)$.

\begin{abstract}
Bay leaf (Laurus nobilis L.) has been shown to possesses various biological activities such as wound healing activity, antioxidant activity, antibacterial activity, antiviral activity, immunostimulant activity, anticholinergic activity, antifungal activity, insect repellant activity, anticonvulsant activity, antimutagenic activity, and analgesic and anti-inflammatory activity. The present study aimed to investigate whether the bay leaf incense (BL) elicits the memory formation via the action on the cholinergic system using a scopolamine (Sco)-induced rat model. Rats were exposed to BL over $5 \mathrm{~min}$ in a smoking chamber apparatus once daily for 22 days, whereas memory impairment was induced by Sco $(0.7 \mathrm{mg} / \mathrm{kg})$, a muscarinic receptor antagonist, delivered $30 \mathrm{~min}$ before each behavioral test. The phytochemical composition of BL was achieved by gas chromatograph-mass spectrometry (GCMS). Behavioral effects in rats were assessed by Y-maze, radial arm maze (RAM), and novel object recognition (NOR) paradigms. Additionally, the acetylcholinesterase (AChE) activity and the oxidative stress markers in the rat hippocampus were also evaluated. Exposure to BL significantly ameliorated Sco-induced cognitive impairment and oxidative stress in the rat hippocampus. The obtained results suggested that BL-induced ameliorative cognitive effects are mediated by enhancement of the cholinergic system and antioxidant activities.
\end{abstract}

Keywords: Laurus nobilis; bay leaf; incense; scopolamine; cholinergic system; memory; oxidative stress

\section{Introduction}

Cholinergic neurotransmission has been implicated in a variety of disease states [1]. In several types of dementia, including Alzheimer's disease (AD), the cholinergic system is recognized as a significant factor because acetylcholine (ACh) plays an important role in cognitive processes [2]. A variety of cholinergic drugs has been approved in clinical trials to treat or enhance AD, exerting therapeutic effects by preventing ACh insufficiency and thereby increasing ACh levels in the brain, hydrolyzed by acetylcholinesterase (AChE) [3]. A meta-analysis of 26 studies of donepezil, rivastigmine, and galantamine reported a modest but clinically significant overall benefit of these drugs for cognition, function, behavior, and global clinical change stabilization [4]. The AChE inhibitors, such as donepezil, rivastigmine, and galantamine are the most common drugs prescribed for the treatment of AD because they temporarily increase ACh availability in cholinergic synapses [5]. The use of cholinergic medications for AD has limitations because they tended to cause adverse 
effects, such as pain, nausea, and hepatotoxicity [6,7]. Alternative treatment options are therefore required for $\mathrm{AD}$ patients.

Scopolamine (Sco) administration may be considered as a psychopharmacological model of AD [8]. Sco, an antagonist of the muscarinic receptor, inhibits the activity of the muscarinic acetylcholine receptor and the concomitant occurrence of temporary cognitive amnesia and electrophysiological changes close to those seen in AD $[9,10]$. Supporting evidence suggested that Sco-induced cognitive deficits via cAMP/SIRT1/Akt/Bcl-2 pathway [11] and also mediated brain oxidative stress [12]. Besides, growing evidence indicates that Sco interferes with extracellular signal-regulated kinase (ERK) and cAMP response element-binding (CREB)/brain-derived neurotrophic factor (BDNF) molecular homeostasis in animal models $[13,14]$ while simulating ERK/CREB/BDNF injury in the brains of $\mathrm{AD}$ patients [15]. The Sco-induced model exhibited reduced ACh levels and choline acetyltransferase (ChAT) activity, with an increase in AChE activity in a previous study [16].

Laurus nobilis L. (Lauraceae) is a shrub that is native to the Mediterranean area and cultivated in a range of Asian countries, Europe as a spice or used as an ornamental plant, and the Americas [17,18]. Bay laurel (L. nobilis L.) leaves, sometimes referred to as laurel, noble laurel, sweet bay, or sweet laurel, have long been used for flavoring foods, particularly in Mediterranean cuisine as well as in cosmetology [19]. The leaves are traditionally used as a carminative, stomachic, and nervine $[17,20]$, as well as in the treatment of amenorrhea, colic, condylomata, hysteria, polyps, sclerosis, and spasms [21]. In Iranian folk medicine, the leaves are used to treat epilepsy, neuralgia, and parkinsonism [21].

The chemical composition of the bay laurel leaves has been extensively studied. 1,8 -Cineole (30.8\%) has been identified to be the main compound followed by $\alpha$-terpinyl acetate $(14.9 \%)$, $\alpha$-terpineol $(8.0 \%)$, sabinene $(7.9 \%)$, terpinen-4-ol $(6.0 \%)$, $\alpha$-pinene $(5.3 \%), \beta$ pinene (3.6\%), methyleugenol (3.6\%), and $\gamma$-terpinene (3.3\%) [17]. Nabila et al. [22] reported 1,8 -cineole $(30.1 \%)$, $\alpha$-terpynyl acetate $(21.6 \%)$ and methyl eugenol $(16.9 \%)$ as the main compounds in the chemical composition of the essential oil of $L$. nobilis leaves. It has been demonstrated that $\alpha$-pinene and 1,8-cineole protected U373-MG cells against $\mathrm{H}_{2} \mathrm{O}_{2}$-induced oxidative injury by attenuating the loss of cell viability and cell morphology, inhibiting reactive oxygen species (ROS) production and lipid peroxidation, while increasing the endogenous antioxidant status [23]. Also, linalool and 1,8-cineole exhibited anticancer activities in lung cancer A549 cells [24]. Sabinene (8.86\%), one of the major compounds from the needles of Abies koreana, contributed to the observed memory-enhancing effect on Sco-induce amnesia in mice [25]. Despite extensive studies about the biological activities of L. nobilis extract, there is currently no study that addressed the benefits of bay leaf incense (BL) in diseases involving brain disfunction, where the incense of the plant is sold with a memory-enhancing claim in Anatolia. Therefore, the present study was organized to elucidate the possible potential effects of BL on memory function and brain antioxidant status of rats exposed to Sco by means of scientific approach.

\section{Materials and Methods}

\subsection{Plant Material}

The leaves of L. nobilis were provided in 2018 by Bakkalim Co, Ltd. (Mersin, Turkey), collected from its natural habitat in the Mediterranean region of Turkey.

\subsection{Gas Chromatography-Mass Spectrometry (GC-MS) Analysis}

Component analysis of the bay leaf smoke was performed using gas chromatography (Agilent 7890A, Agilent, Santa Clara, CA, USA)-mass detector (Agilent 5975C, Agilent, Santa Clara, CA, USA) device and equipped with a DB-5ms column (Agilent, Santa Clara, CA, USA, $30 \mathrm{~m} \times 250 \mu \mathrm{m} \times 0.25 \mu \mathrm{m}$ ). The instrument control parameters included an injection of $0.25 \mu \mathrm{L}$ with helium as the carrier gas, spitless mode, the oven program was $40{ }^{\circ} \mathrm{C}$ for $3 \mathrm{~min}$, then increased $10{ }^{\circ} \mathrm{C} / \mathrm{min}$ to $280^{\circ} \mathrm{C}$ and maintained for $3 \mathrm{~min}$, the flow was set to $1 \mathrm{~mL} / \mathrm{min}$, the purge flow to split vent was $40 \mathrm{~mL} / \mathrm{min}$ at $1 \mathrm{~min}$ and the registered average velocity was $36.262 \mathrm{~cm} / \mathrm{sec}$. The total run time was $30 \mathrm{~min}$ and three 
injections were analyzed consecutively. The results represent the average value for the determinations. All identified compounds were calculated by comparison of the mass spectra to the standards and the literature data in the NIST/Wiley libraries as well as the data available in the Wiley 275 software from the used GC-MS system. The confirmation of each identified compound was verified against the linear retention indices (RI) with the published data in the scientific literature.

\subsection{Animals}

A total of 25 three-month-old male Wistar rats were used in the present study. The animals were housed in a temperature and light-controlled room $\left(22{ }^{\circ} \mathrm{C}\right.$, a 12 -h cycle starting at 08:00 h) with free access to food and water. All experimental procedures were strictly conducted by the Directive 2010/63/EU of the European Parliament and of the Council of 22 September 2010 on the protection of animals with approval from the Ethical Committee (No. 15309/22.07.2019).

\subsection{Drug Treatment and Group Division}

The scheme of drug treatments and behavioral measurements is summarized in Figure 1. Rats were randomly divided into five groups ( $n=5$ animals/group): first group — control; the second group — received donepezil treatment (DP, $5 \mathrm{mg} / \mathrm{kg}$, SigmaAldrich, Darmstadt, Germany), as the positive control in the Y-maze, the novel object recognition and the radial arm-maze tests); the third group-received bay leaf incense (BL); the fourth group — scopolamine (Sco, $0.7 \mathrm{mg} / \mathrm{kg}$, Sigma-Aldrich, Darmstadt, Germany) and fifth group-Sco received $\mathrm{BL}(\mathrm{Sco}+\mathrm{BL})$. Also, we confirm that $n=5$ animals/group is appropriate using InVivoStat, and R-based statistical package [26]. Based on a significance level of 0.05 , the power to detect a $20 \%$ biologically relevant change from control is $90 \%$. Rats were subjected to BL for 5 min during 7 days before starting behavioral tests and continuously administered during behavioral tests (22 days). The control and BL groups were intraperitoneally (i.p.) injected with $0.9 \%$ physiological saline. DP $(5 \mathrm{mg} / \mathrm{kg}$, SigmaAldrich, Darmstadt, Germany) and Sco (0.7 mg/kg, Sigma-Aldrich, Darmstadt, Germany) were dissolved in $0.9 \%$ physiological saline and i.p. injected, once daily, 30 min before the Y-maze, the novel object recognition and the radial arm-maze tests [27].

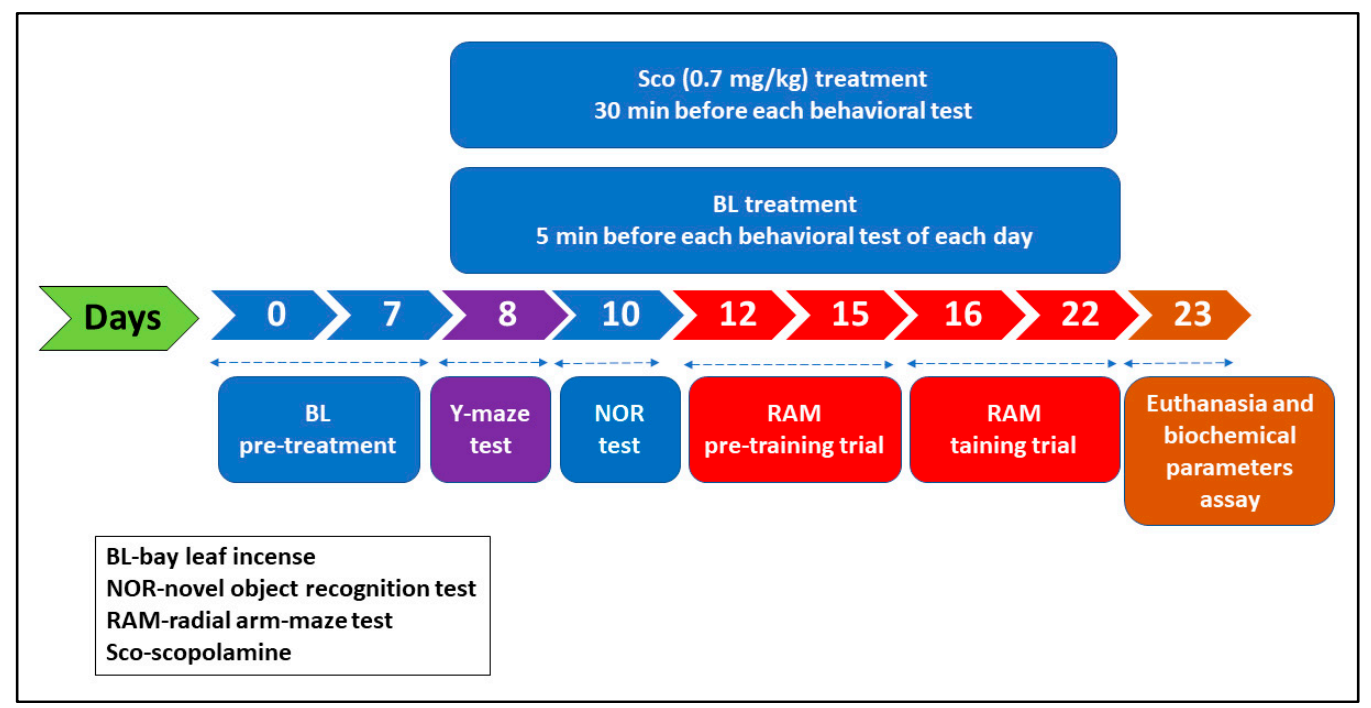

Figure 1. Schematic representation of drug treatment and behavioral analysis.

\subsection{Exposure Chamber}

Rats were exposed to BL following the method described by Merali et al. [28]. Before behavioral tests, rats were individually placed within the exposure chamber for $5 \mathrm{~min}$. The exposure chamber was connected via rubber latex tubing to a vaporizing chamber 
containing a heating coil and was also connected to an electric pump, which created a gentle vacuum to pull the BL through to the exposure chamber. The animals in the control, DP, and Sco groups were subjected to similar conditions, except that the tube from the heating coil was disconnected to allow for the entry of fresh air. Separate exposure chambers and tubing were used for control and experimental groups.

\subsection{Behavioral Assessments}

\subsubsection{Y-Maze Spontaneous Alternation Test}

Short-term spatial memory was assessed by recording spontaneous alternation behavior in a single-session Y-maze as previously described by Jackson [29] and Boiangiu et al. [27]. At $5 \mathrm{~min}$ after BL inhalation, each rat was placed at the end of one arm and allowed to explore the Y-maze freely for $8 \mathrm{~min}$. The number of arm entries and sequence of arm visits were recorded using ANY-maze ${ }^{\circledR}$ software (Stoelting CO, Wood Dale, IL, USA). Besides, the spontaneous alternation percentage was calculated as (number of alternation/total entries-2) $\times 100$.

\subsubsection{Radial Arm-Maze}

The radial arm-maze test (RAM) was used to explore working memory as well as reference memory for 5 min session after inhaling the BL as previously described by Olton and Samuelson [30] and Boiangiu et al. [27]. ANY-maze ${ }^{\circledR}$ software (Stoelting CO, Wood Dale, IL, USA) was used to record the movements of rats inside the RAM. Before the training trial, there were four days of habituation sessions. During the training sessions (one trial per day for one week), the performance of individual rats was evaluated by the number of working memory errors (number of entries into baited arms visited before) and number of reference memory errors (number of entries into nonbaited arms).

\subsubsection{Novel Object Recognition}

The preference of novelty in rodents and the memory abilities were detected by a novel object recognition (NOR) task according to a method described previously by Foyet et al. [31]. The preference of a novel object may indicate the existence of familiar object presentation in the memory of a rat [32]. The animal behavior was analyzed by ANYmaze $^{\circledR}$ software (Stoelting CO, Wood Dale, IL, USA). The test equipment consisted of an open box $(72 \mathrm{~cm} \times 72 \mathrm{~cm} \times 36 \mathrm{~cm})$ in which rats were placed for two consecutive sessions (T1 and T2) with and an inter-trial interval of $1 \mathrm{~h}$. The "sample" trial (T1) comprising two identical objects, whereas during the "choice" trial (T2), one familiar object (F) was replaced by a novel object $(\mathrm{N})$, and the animal behavior was recorded for $5 \mathrm{~min}$. T1 was performed at $5 \mathrm{~min}$ after BL inhalation. The discrimination index (DI) was calculated as the time spent in exploring $\mathrm{N}(\mathrm{TN})$ - the time spent in exploring $\mathrm{F}(\mathrm{TF}) / \mathrm{TN}+\mathrm{TF}$. Exploration was defined as sniffing or touching the object with the nose and/or forepaws. Sitting on the object was not considered exploration.

\subsection{Measurement of the Biochemical Parameters}

For biochemical assays, rats were deeply anesthetized (pentobarbital sodium, $150 \mathrm{mg} / \mathrm{kg}$, b.w., i.p., Tokyo Chemical Industry, Tokyo, Japan), and decapitated for brain extraction. For homogenate preparation (1:10), hippocampi were centrifuged $\left(15 \mathrm{~min}\right.$ at $\left.960 \times g, 4{ }^{\circ} \mathrm{C}\right)$ with ice-cold $0.1 \mathrm{M} \mathrm{KH}_{2} \mathrm{PO}_{4}$ buffer (pH 7.4) containing $1.15 \% \mathrm{KCl}$ using a Potter Homogenizer (Cole-Parmer, Vernon Hills, IL, USA). The obtained supernatant was further assayed to investigate the AChE, superoxide dismutase (SOD), and catalase (CAT) specific activities, the total content of reduced glutathione (GSH), protein carbonyl, and malondialdehyde (MDA) levels.

\subsubsection{Determination of the AChE Activity}

To measure the AChE (EC 3.1.1.7), the method of Ellman et al. [33] was used. The reaction mixture $(600 \mu \mathrm{L})$ consisted of $0.26 \mathrm{M}$ phosphate buffer with $\mathrm{pH} 7.4,1 \mathrm{mM} 5.5^{\prime}$ - 
dithio-bis-2 nitrobenzoic acid (DTNB), and $5 \mathrm{mM}$ acetylthiocholine chloride (ATC). The absorbance of the solution was read at $412 \mathrm{~nm}$. The AChE activity was expressed as nmol of $\mathrm{ACT} / \mathrm{min} / \mathrm{mg}$ of protein.

\subsubsection{Determination of the SOD Activity}

Superoxide dismutase (SOD, EC 1.15.1.1) activity was determined using a procedure described by Winterbourn et al. [34]. The reaction mixture $(1.5 \mathrm{~mL})$ consisted of $100 \mathrm{mM}$ TRIS/HCl (pH 7.8), 75 mM NBT, $2 \mu \mathrm{M}$ riboflavin, 6 mM EDTA and $200 \mu \mathrm{L}$ supernatant. The absorbance was measured at $560 \mathrm{~nm}$. One unit of SOD activity was defined as the amount of enzyme causing $50 \%$ inhibition in the tetrazolium dye reduction rate. The enzyme activity was reported in $\mathrm{U} / \mathrm{mg}$ protein.

\subsubsection{Determination of the CAT Activity}

The catalase (CAT, EC 1.11.1.6) activity was measured based on the method described by Sinha [35]. The reaction mixture consisted of $150 \mu \mathrm{L}$ phosphate buffer (0.01 M, pH 7.0) and $100 \mu \mathrm{L}$ supernatant. The absorbance was read at $570 \mathrm{~nm}$. The activity of the enzyme was expressed as $\mu \mathrm{mol}$ of $\mathrm{H}_{2} \mathrm{O}_{2}$ consumed $/ \mathrm{min} / \mathrm{mg}$ protein.

\subsubsection{Determination of the Protein Carbonyl Level}

The method to determine the carbonylated protein levels, according to Oliver et al. [36] and modified through Luo and Wehr [37], is based on the reaction of 2,4-dinitrophenylhydrazine (DNPH) with the carbonyl groups of proteins. The results were expressed as nmol/mg protein.

\subsubsection{Determination of the MDA Level}

To measure malondialdehyde (MDA) level, the method described by Ohkawa et al. [38] was employed. This method is based on the reaction of MDA, an aldehyde resulting from oxidative damage to cellular lipid membranes with thiobarbituric acid, resulting in a pink color, determined by a colorimetric method, measured in a spectrophotometer at $532 \mathrm{~nm}$. The results were presented as $\mathrm{nmol} / \mathrm{mg}$ protein.

\subsubsection{Estimation of the Protein Content}

To determine the total protein, the method described by Smith et al. [39] was used. A bicinchoninic acid (BCA) protein assay kit (Sigma-Aldrich, Darmstadt, Germany) was used for the quantification of total protein.

\subsection{Statistical Analysis}

All data were expressed as the mean \pm standard error of the mean (S.E.M.). GraphPad Prism 7.0 software (La Jolla, CA, USA) was used to evaluate the obtained data. The data from different treatment groups were compared using one-way analysis of variance (ANOVA) followed by Tukey's post hoc multiple comparison test. Differences were considered statistically significant at $p<0.05$. Statistical correlations were expressed as Pearson correlation coefficient $(r)$.

\section{Results and Discussion}

\subsection{Phytochemical Analysis}

The bay leaf smoke was analyzed by GC-MS analysis (Figure 2), and its chemical composition was presented in Table 1.37 compounds, corresponding to $97.29 \%$ of the total smoke were identified in the bay leaf smoke. Although the GC-MS analysis allowed us to identify only $97.29 \%$ of the total components present in the BL, the rest up to $100 \%(2.71 \%)$ included various substances as traces (each found in less than $0.2 \%$ ) mainly represented by alkanes which we considered the pyrolysis artifacts and nonsignificant for our tests because their presence in the chromatogram is mainly in the second half. This indicates a higher mass lower volatility as compared to monoterpenes. However, their presence in the animal brain needs further testing and represents the basis of our future research. The most abun- 
dant chemical classes of the smoke components were oxygenated monoterpenes (44.84\%), followed by oxygenated compounds $(23.27 \%)$, sesquiterpenes $(22.40 \%)$, and monoterpene hydrocarbons $(6.78 \%)$. The major components of the bay leaf smoke were methyl dihydrojasmonate (14.72\%), 1,8-cineole (12.61\%), terpinen-4-ol (6.92\%), trans-caryophyllene oxide $(5.00 \%)$, carvacrol $(4.76 \%)$, and citronellal $(4.04 \%)$. This indicated that the obtained volatile compounds were from a 1,8-cineole chemotype laurel. However, significant amounts of sesquiterpenes and other types of oxygenated compounds were identified as well. All monoterpenes amounted to $50 \%$ of the volatiles, whereas sesquiterpenes were around half of the monoterpene quantity. Caryophyllene oxide, cubebene, and caryophyllene were the predominant sesquiterpenes. Nevertheless, the eight sesquiterpene compounds were all above $1 \%$. Although most of the identified compounds possess fragrant, antimicrobial, repellant, anti-infective, and plant hormone properties, their combination, and ratio present a diversity of putative effects. The majority of the volatile substances found in lower concentrations in our sample may play an important role in enhancing the bioavailability of the main compounds. This is explained by the tensioactive properties of such volatiles in pharmaceutical technology essential oils being used as promoters for the absorption of active compounds [40]. Essential oils are complex mixtures of various small molecules substances and their chemical composition is highly influenced by environmental factors and processing technology. On the other hand, even if it uses the same raw material as an essential oil the incenses or smoke obtained by direct burning of the vegetal product comprises a different spectrum of compounds. This is mainly because the burning induces direct pyrolysis of the plant material and it takes a shorter amount of time than usual hydrodistillation. In our study we investigated the incense obtained during the first $5 \mathrm{~min}$ of burning, considering that this process leads to artifacts and metabolites that can suffocate the animals if inhaled for longer.

Table 1. The chemical composition (\%) of L. nobilis L. leaf smoke.

\begin{tabular}{cccc}
\hline No. & Compound & RI & Composition (\%) \\
\hline 1. & $\alpha$-Thujene & 930 & 0.51 \\
2. & $\alpha$-Pinene & 939 & 0.29 \\
3. & Sabinene & 977 & 0.52 \\
4. & L- $\beta$-Pinene & 982 & 0.14 \\
5. & Myrcene & 991 & 1.58 \\
6. & $p$-Cymene & 1025 & 0.70 \\
7. & L-Limonene & 1028 & 1.94 \\
8. & $\alpha$-Fenchene & 1060 & 0.28 \\
9. & $\alpha$-Terpinene & 1078 & 0.82 \\
& Monoterpene hydrocarbons & & 6.78 \\
10. & Linalool & 1103 & 0.87 \\
11. & Orange/Rose oil & 1124 & 2.25 \\
12. & cis-Limonene oxide & 1138 & 1.13 \\
13. & Pinocarvone & 1163 & 0.56 \\
14. & Citronellal & 1170 & 4.04 \\
15. & $1,8-$-Cineole & 1183 & 12.61 \\
16. & L-(-)-Menthol & 1185 & 1.11 \\
17. & Terpinen-4-ol & 1187 & 6.92 \\
18. & L- $\alpha$-Terpineol & 1189 & 0.64 \\
19. & (R)-(+)-beta- & 1237 & 1.11 \\
20. & Citronellol & 1246 & 1.70 \\
21. & D(+)-Carvone & 1256 & 0.70 \\
22. & Geraniol & 1258 & 0.24 \\
23. & Cinnamic aldehyde & 1267 & 1.48 \\
24. & Carvacrol & 1298 & 4.76 \\
25. & Piperonal & 1300 & 2.46 \\
\hline
\end{tabular}


Table 1. Cont.

\begin{tabular}{cccc}
\hline No. & Compound & RI & Composition (\%) \\
\hline 26. & Eugenol & 1329 & 2.26 \\
& Oxygenated monoterpenes & & 44.84 \\
27. & trans-Caryophyllene & 1418 & 3.75 \\
28. & Cyclamen aldehyde & 1434 & 1.38 \\
29. & $\alpha$-Amorphene & 1452 & 2.08 \\
30. & Seychellene & 1464 & 1.97 \\
31. & $\alpha$-Cubebene & 1469 & 4.25 \\
32. & $\alpha$-Curcumene & 1477 & 1.02 \\
33. & trans-Caryophyllene & 15.81 & 5.00 \\
34. & oxide & 1616 & 2.95 \\
35. & E-cis- $\beta$-Santalol & 1525 & $\mathbf{2 2 . 4 0}$ \\
36. & Sesquiterpenes & 1755 & 3.71 \\
37. & Acetyleugenol & 2276 & 14.72 \\
& Olivetol & & $\mathbf{2 3 . 2 7}$ \\
& Methyl & & $\mathbf{9 7 . 2 9}$ \\
\hline
\end{tabular}

${ }^{*}$ placed in this position because it is not a sesquiterpene.

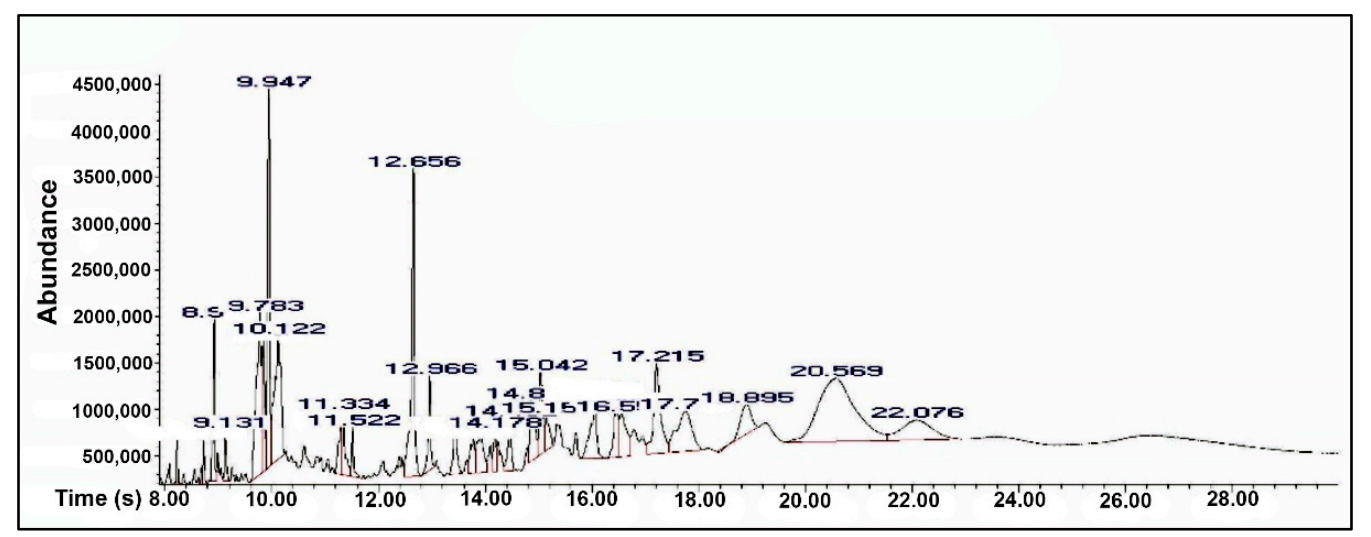

Figure 2. Gas chromatography-mass spectrometry (GC-MS) profile of the L. nobilis leaves smoke.

Today, little is known of the direct implications of the volatiles on the brain, especially the synergistic and multitarget approach of such compounds. Most of the research was directed on monoterpenes containing hydroxyl groups (such as linalool, eugenol, terpineol, terpinene-4-ol, etc.) and their synergistic effects with antibiotics enhancing the antimicrobial activity. However, the activity is correlated with the chirality, the size, the shape, and the physicochemical properties of the molecule and its interaction and integration in the cell membranes influencing the integrity/permeability, receptors, ionic channels, enzymatic systems, etc. [41-43]. Interestingly, the isomers of the volatile compounds can modify the odour, the taste, and the effects on the organisms.

Previous data states that linalool and its derivatives have a great impact on the central nervous system (CNS) by interacting either with $\mathrm{Ca}^{2+}$ channels or by interfering with the muscarinic receptors, thus inducing anxiolytic and antidepressant effects. Similar effects and mechanisms have been postulated also for limonene, carvone, and O-methyl jasmonate. The lipophilic character of the compounds allows an easy passage through the blood-brain barrier. Such direct effects on the limbic systems have been proven for the first time for 1,8-cineole [44].

Our data agrees with many other authors working on L. nobilis essential oil. Dammak et al. [45] reported that 1,8-cineole was the most abundant compound of L. nobilis essential oil (43.2 $\pm 1.7 \%)$. Other main components of this essential oil were found to be $\beta$-terpinyl acetate $(13.7 \pm 1.9 \%)$, eugenol methyl ether $(11.7 \pm 1.8 \%)$, linalyl acetate 
$(5.8 \pm 0.6 \%)$, sabinene $(4.1 \pm 0.9 \%), \alpha$-pinene $(4.1 \pm 0.3 \%)$, as well as terpinen-4-ol $(3.6 \pm 0.3 \%)$ and $\beta$-pinene $(3.2 \pm 0.9 \%)$. Taban et al. [46] mentioned the presence of $\alpha$-pinene $(2.94-4.11 \%), \beta$-pinene $(2.51-3.22 \%)$, cis-sabinene hydrate $(0.49-1.03 \%)$, eugenol (0.55-1.03\%), methyleugenol (2.34-3.99\%) and trans-caryophyllene (0-1.33\%) in the chemical composition of the L. nobilis essential oil. Constituent analysis indicated the presence of volatile compounds such as isoeugenol (53.50\%), myrcene (16.60\%), and chavicol (10.20\%) in the chemical composition of the L. nobilis essential oil [47]. In the analysis of the essential oil of L. nobilis leaves, Al-Kalaldeh et al. [48] reported 1,8-cineole (40.91\%) as the major component, followed by $\alpha$-pinene $(5.82 \%)$, $\beta$-pinene $(4.55 \%)$, sabinene $(6.92 \%)$, limonene $(2.10 \%)$, linalool $(1.29 \%)$, and $\alpha$-terpinyl acetate (5.86\%). Upon these studies, we concluded that our BL has a chemical composition comparable to those reported by other groups and could support its cognitive-enhancer and antioxidant profile.

\subsection{Effects of Bay Leaf Incense (BL) on Memory Formation in Behavioral Tasks}

To explore whether BL exposure attenuated Sco-induced cognitive impairment in rats, the Y-maze, radial arm-maze (RAM), and novel object recognition (NOR) tests were conducted. For the Y-maze test, the Sco administered group demonstrated an increase of locomotor activity, as evidenced by a significant increase $(p<0.0001)$ of the number of arm entries compared to the control group (Figure 3A). When Sco was injected, a significant decrease of short-term memory performance was observed, as evidenced by decreased spontaneous alternation percentage $(p<0.001)$ compared with the control group (Figure 3B). Moreover, significant improvement of the spontaneous alternation percentage $(p<0.001)$ was observed in Sco-injected rat following BL exposure when compared to Sco-induced rats, indicating that the memory impairment induced by Sco was reversed. Compared with the control group, in the RAM, rats treated with Sco showed increased number of working memory errors (Figure 3C) $(p<0.0001)$, and number of reference memory errors (Figure 3D) $(p<0.0001)$. However, rats treated with Sco and BL showed significantly reduced number of working memory errors (Figure 3C) $(p<0.0001)$, and the number of reference memory errors (Figure 3D) $(p<0.01)$, when compared to the Sco-treated group. When BL and DP, a standard drug for AD, were administered, significant effects on memory performance in the Y-maze and RAM tests were noticed.

Based on the outcomes, the Sco groups showed decreased discrimination index of the $\mathrm{N}$ (Figure $4 \mathrm{~A})(p<0.01)$ as compared to the control group, while exhibited the same preference to explore both $\mathrm{F}$ and $\mathrm{N}$, indicating an impaired response to recognizing the $\mathrm{N}$. The Sco-treated rats subjected to BL, displayed significant increase $(p<0.001)$ in both discrimination index (Figure $4 \mathrm{~A}$ ) and the time to explore the $\mathrm{N}$ (Figure $4 \mathrm{~B}$ ), suggesting a positive response to novelty. Both BL and DP significantly increased performance in the NOR, suggesting positive effects on recognition memory. 


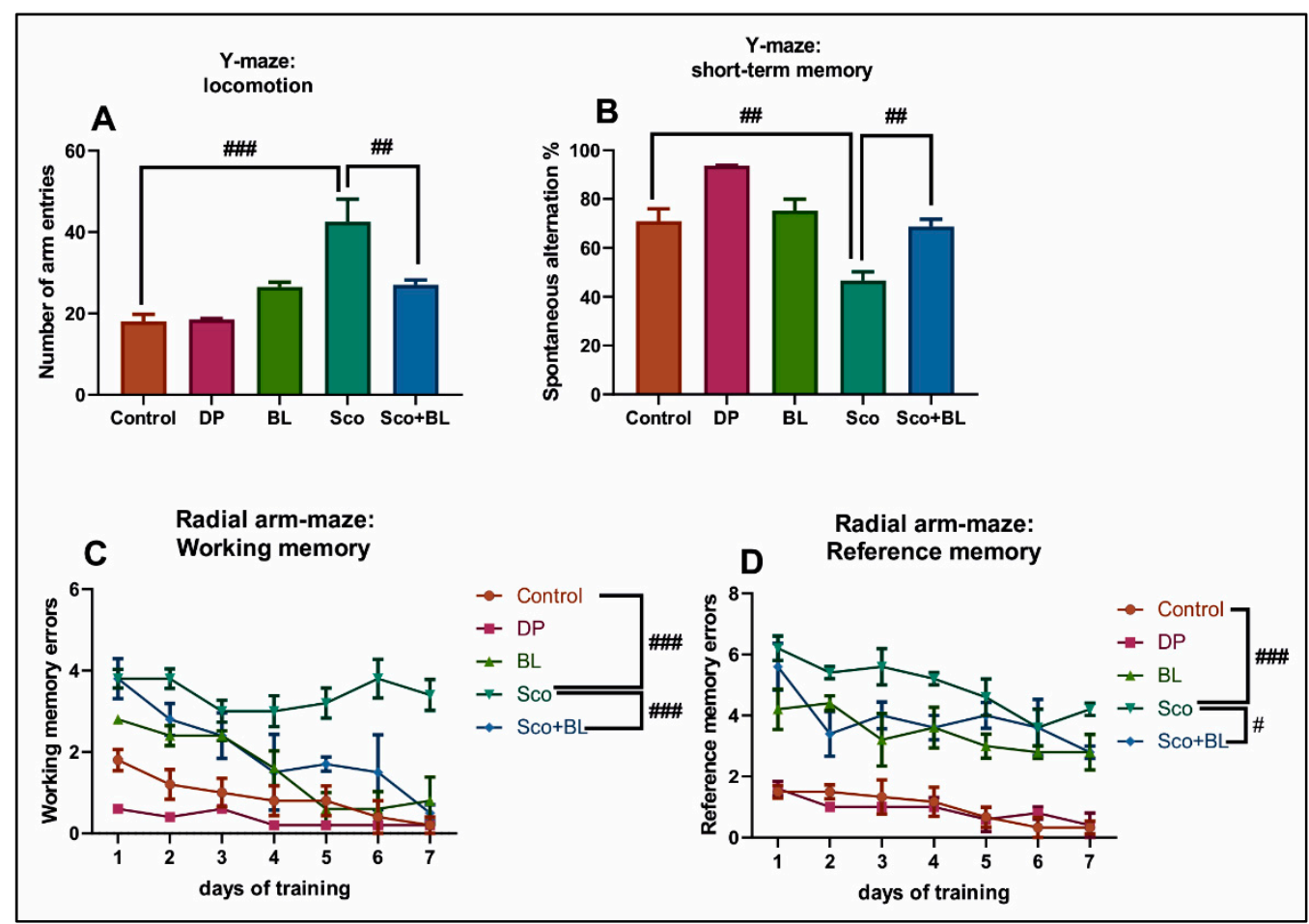

Figure 3. Behavioral analysis for the Y-maze and the radial-arm maze (RAM) tests. (A) represents the graph for the number of entries in the Y-maze test in different groups; (B) represents the graph for the spontaneous alternation percentage in the Y-maze test in different groups; (C) represents the graph for the working memory errors in RAM in different groups; (D) represents the graph for the reference memory errors in RAM in different groups. Data are expressed as means \pm SEM ( $n=5$ and statistical analysis by one-way ANOVA followed by Tukey's post hoc analyses: (A) Control vs. Sco: \#\#\# $p<0.0001$, and Sco vs. Sco + BL: \#\# $p<0.001$; (B) Control vs. Sco: \#\# $p<0.001$, and Sco vs. Sco + BL: \#\# $p<0.001$; (C) Control vs. Sco: \#\#\# $p<0.0001$, and Sco vs. Sco + BL: \#\#\# $p<0.0001$; (D) Control vs. Sco: \#\#\# $p<0.0001$, and Sco vs. Sco + BL: \# $p<0.01$.

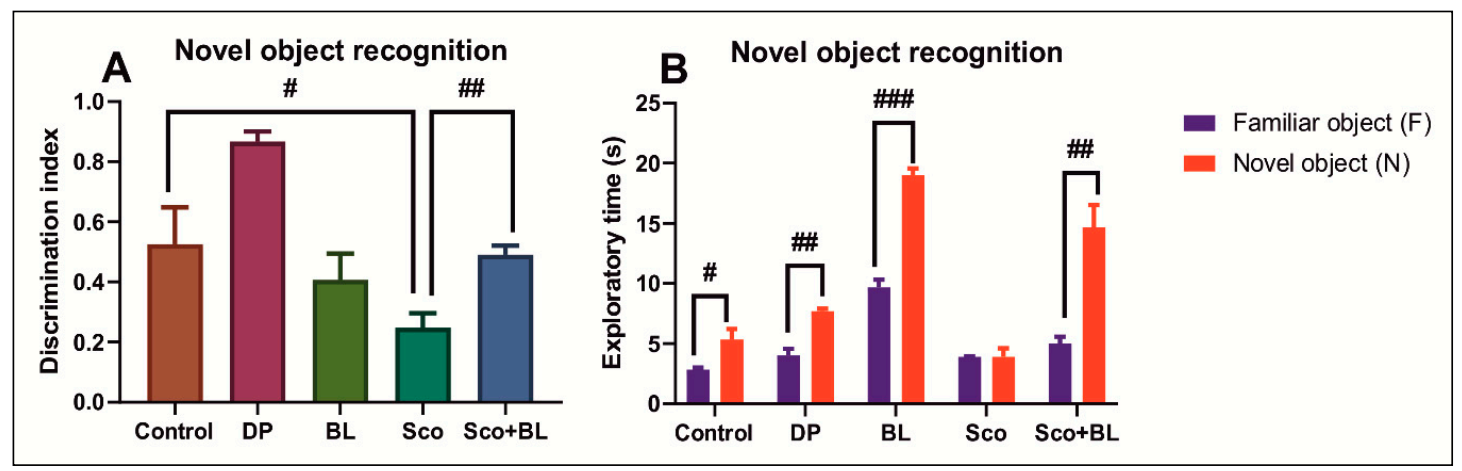

Figure 4. Behavioral analyses for the novel object recognition (NOR) test. (A) represents the graph for the discrimination index in different groups; (B) represents the graph for the exploratory time (s) in different groups. Data are means \pm S.E.M. $(n=5)$ and statistical analysis by one-way ANOVA followed by Tukey's post hoc analyses: (A) Control vs. Sco: \# $p<0.01$; Sco vs. Sco + BL: \#\# $p<0.001 ;$ (B) \# $p<0.01 ; \# \#<0.001$ and \#\#\# $p<0.0001$.

Few studies are describing the potential effects of L. nobilis against AD-relevant insults, consistent with our data obtained in the current study. People around the world have also used bay leaves in traditional and complementary medicine practices for hundreds of years. It has been demonstrated that bay leaf burning offers a range of health benefits. Anxiety relief is touted as a major benefit of bay leaf burning. This is probably because bay leaf smoke contains linalool, a compound found in several other plants. 
Pacifico et al. [49] demonstrated that L. nobilis leaf extracts have neuroprotective potential and anti-amyloidogenic efficacy. It has been reported that the chloroform fraction of L. nobilis was able to protect against cerebral ischemia neuronal damage [50]. Correspondingly, the apolar L. nobilis leaf extracts exhibited neuroprotective action toward three nervous system cell lines [51]. Moreover, some of the major compounds identified in the chemical composition of our L. nobilis used samples, supported its cognitive-enhancing profile. Lee et al. [52] demonstrated the neuroprotective potentials of $\alpha$-pinene against Sco-induced learning and memory impairment in C57BL/6 mice. Moreover, the authors reported that $\alpha$-pinene significantly increased the spontaneous alternation percentage in the Y-maze test, enhanced spatial recognition in the Morris water-maze test by reducing the escape latency, and increased step-through-latency in the passive avoidance test in the Sco-induced model. Recently, our group demonstrated that an essential oil mix containing $\beta$-pinene $(1.76 \%), \alpha$-pinene $(1.01 \%)$, linalool $(0.55 \%)$, and cymene $(0.53 \%)$ produced an improving effect on the consolidation of NOR memory [27]. Goto et al. [53] demonstrated a significant improvement of the cognitive function of elderly people following 1,8-cineole exposure. 1,8-cineole was previously proven to be a good anti-inflammatory and antinociceptive agent in mice models, whereas its isomer 1,4-cineole demonstrated good anxiolytic effects [54]. Interestingly, the main oxygenated compound identified in our sample, methyl dihydrojasmonate (syn. hedione) promotes neuronal health as indicated by Pavan et al. [55]. Moreover, this compound proved to be efficient in neurodegenerative diseases associated with pigmentation problems due to its binding to the vomeronasal type-1 receptor 1 (VN1R1) found in the amygdala and hippocampus. Furthermore, olivetol is recognized as a diphenol cannabinoid compound with antioxidant and anticholinergic properties [56]. In line with these results, our in vivo findings confirm the ability of the BL to usefully modulate and enhance cholinergic neuronal transmission and cognitive performance under dementia-related conditions.

\subsection{Effects of Bay Leaf Incense (BL) on AChE-Inhibiting Activity}

In memory and cognitive functions, the cholinergic transmission plays a significant role. The enzyme AChE is responsible for the degradation of $\mathrm{ACh}$ into acetate and choline and decreases neurotransmitter levels in the brain, as can be noticed in the cholinergic dysfunction of AD [57]. Acetylcholinesterase inhibitors (AChEIs) increase the amount of ACh, improving memory functions. People with AD are commonly treated with procognitive medicines. However, the hepatotoxicity and the side effects arising from the activation of the cholinergic system limit the use of AChEIs $[58,59]$. The effect of BL on the AChE activity in the rat hippocampus caused by Sco is shown in Figure 5A. The activity of AChE significantly increased $(p<0.001)$ in the Sco-treated group as compared to the control group. However, the activity of AChE in the administration of the BL significantly decreased $(p<0.0001)$ compared to the Sco-treated group. DP and BL exhibited anti-AChE activities. Our results demonstrated the high anti-AChE activity of the BL. These outcomes are in line with few past investigations which reported the anti-AChE activity of the Laurus extract. Gazwi et al. [60] demonstrated that Laurus leaf extract significantly restored AChE of the brain in lead-treated rats, proposing that Laurus extract could preserve living organisms against neurotoxicity by reversing the AChE imbalance caused by lead. This anti-AChE activity of the extract could be attributed to its phenolic and flavonoids contents and its antioxidant activity. Ferreira et al. [61] showed that L. nobilis extract exhibited high AChE inhibitory activity due to the presence of flavonoids. Our data suggest that the memory enhancement effects of BL in Sco-induced amnesic rats could be attributed to the inhibition of the AChE activity and restored of the cholinergic system activity. 


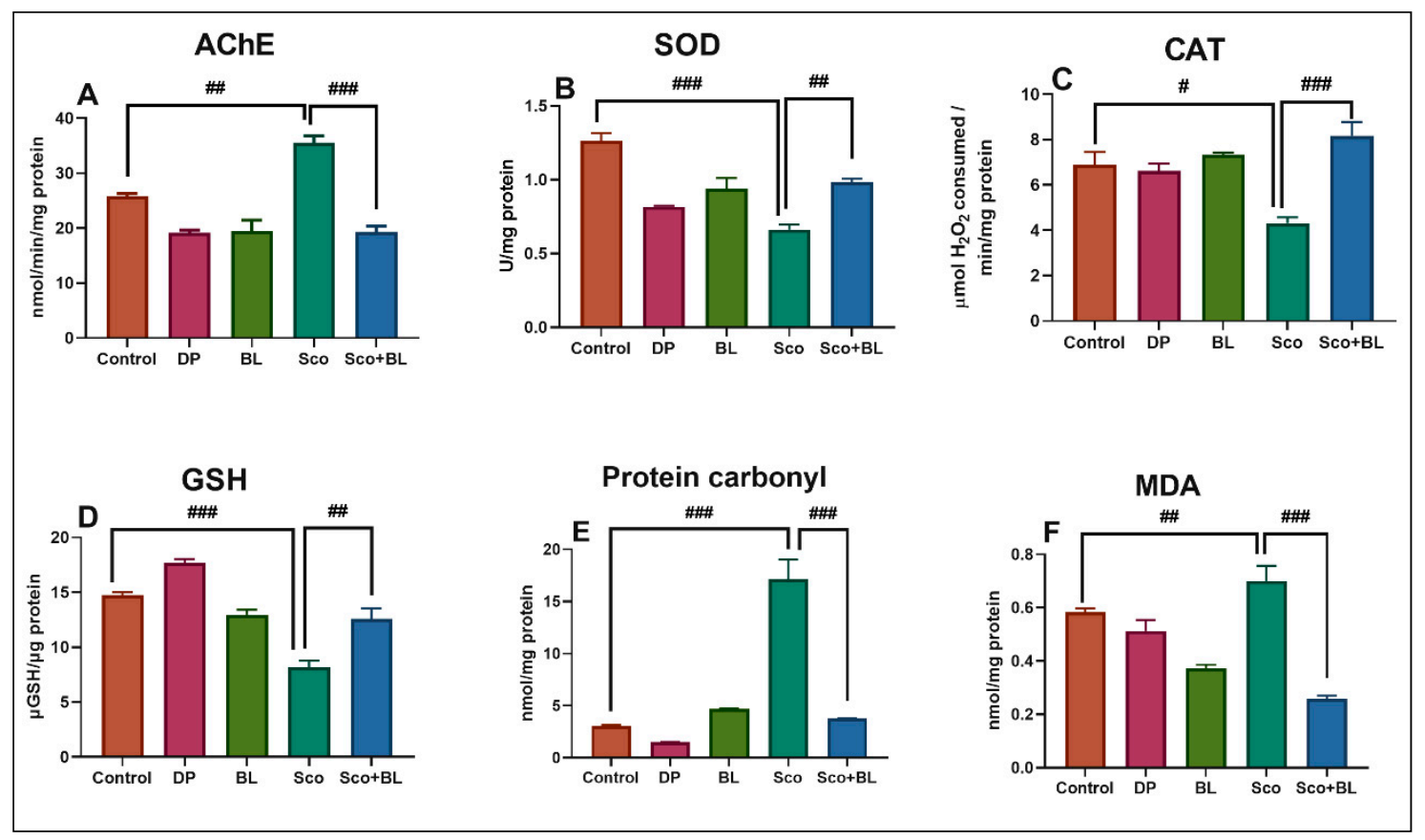

Figure 5. Effects of the bay leaf incense (BL) on (A) AChE; (B) superoxide dismutase (SOD); (C) glutathione peroxidase (GPX) specific activities; (D) reduced glutathione (GSH); (E) protein carbonyl and (F) malondialdehyde (MDA) level. Values represent means \pm S.E.M. $(n=5)$ followed by Tukey's post hoc analyses: (A) Control vs. Sco: \#\# $p<0.001$, Sco vs. Sco + BL: $\# \# \#$ p 0.0001; (B) Control vs. Sco: \#\#\# $p<0.0001$, Sco vs. Sco + BL: \#\# $p<0.001$; (C) Control vs. Sco: \# $p<0.01$, Sco vs. Sco + BL: \#\#\# $p<0.0001$; (D) Control vs. Sco: \#\#\# $p<0.0001$, Sco vs. Sco + BL: \#\# $p<0.001$; (E) Control vs. Sco: \#\#\# $p<0.0001$, Sco vs. Sco + BL: \#\#\# $p<0.0001 ;$ (F) Control vs. Sco: \#\# $p<0.001$, Sco vs. Sco + BL: \#\#\# $p<0.0001$.

\subsection{Effects of Bay Leaf Incense (BL) on the Hippocampus Oxidative Status}

The condition of oxidative stress may be used to assess the hippocampus state of Sco-treated rats [62]. Sco exhibited pro-oxidant activity, as evidenced by suppressed activity of SOD $(p<0.001)$ (Figure 5B), CAT $(p<0.01)$ (Figure 5C), the total content of reduced GSH $(p<0.0001)$ (Figure 5D), along with increased levels of protein carbonyl $(p<0.0001)$ (Figure 5E), and MDA ( $p<0.001$ ) (Figure 5F). As an antioxidant agent, BL exposure restored the antioxidant enzyme activity and decreased the levels of protein carbonyl and lipid peroxidation as compared to Sco-treated animals.

Oxidative stress is one of the pathways responsible for Sco-induced amnesia. The pro-oxidative effects of Sco have been documented as it decreases the activity of antioxidant enzymes such as SOD, CAT, and GPX $[63,64]$ and increased the concentration of malondialdehyde (MDA), which is the main marker of lipids peroxidation [64,65]. Also, numerous studies have shown the pro-cognitive impact of antioxidant compounds on Sco-induced memory damage, possibly by attenuating oxidative stress markers [27,58]. As demonstrated by a substantial increase in SOD and CAT specific activities and the total content of reduced GSH, along with a decrease in protein carbonyl and MDA levels, BL significantly restored the antioxidant status in the brain of rats. The current results are supported by different studies that demonstrated the antioxidant effects of Laurus extract. Hanaa et al. [60] indicated the antioxidant activity of Laurus leaves extract and assumed that it has a defensive role against the oxidative damage caused by lead in a rat's brain. Turkez et al. [66] demonstrated the preventive role of L. nobilis leaf extract in alleviating aluminum phosphide-induced DNA and oxidative damages in vitro. Ham et al. [67] reported that spirafolide from the bay leaf (L. nobilis) prevented dopamine-induced apoptosis by decreasing reactive oxygen species production in human neuroblastoma SH-SY5Y cells. BL exposure effectively restored the antioxidant defense mechanism by increasing the antioxidant levels of activity in the brain. 
To determine the potential association between memory, antioxidant enzymes and lipid peroxidation, the Pearson correlation analysis was used (Figure 6). In this way, a significant negative correlation between the spontaneous alternation $\%$ vs. MDA $(n=5$, $r=-0.703, p<0.01)$ (Figure 6A) and CAT vs. MDA $(n=5, r=-0.776, p<0.0001)$ (Figure 6C) was noticed, suggesting that memory improvement in the Y-maze test is well corelated with a low level of MDA. Also, a decreased activity of AChE is positive correlated with a low level of MDA $(n=5, r=0.772, p<0.0001)$ (Figure 6B). A correlation between the AChE inhibitory action of the ethanolic extract of Laurus leaf and its antioxidants ability in rats was shown by Gazwi et al. [60]. By using Pearson's test, the improvement of spatial memory in behavioral approaches is significantly corelated with the decrease of AChE activity and lipid peroxidation level following BL exposure.

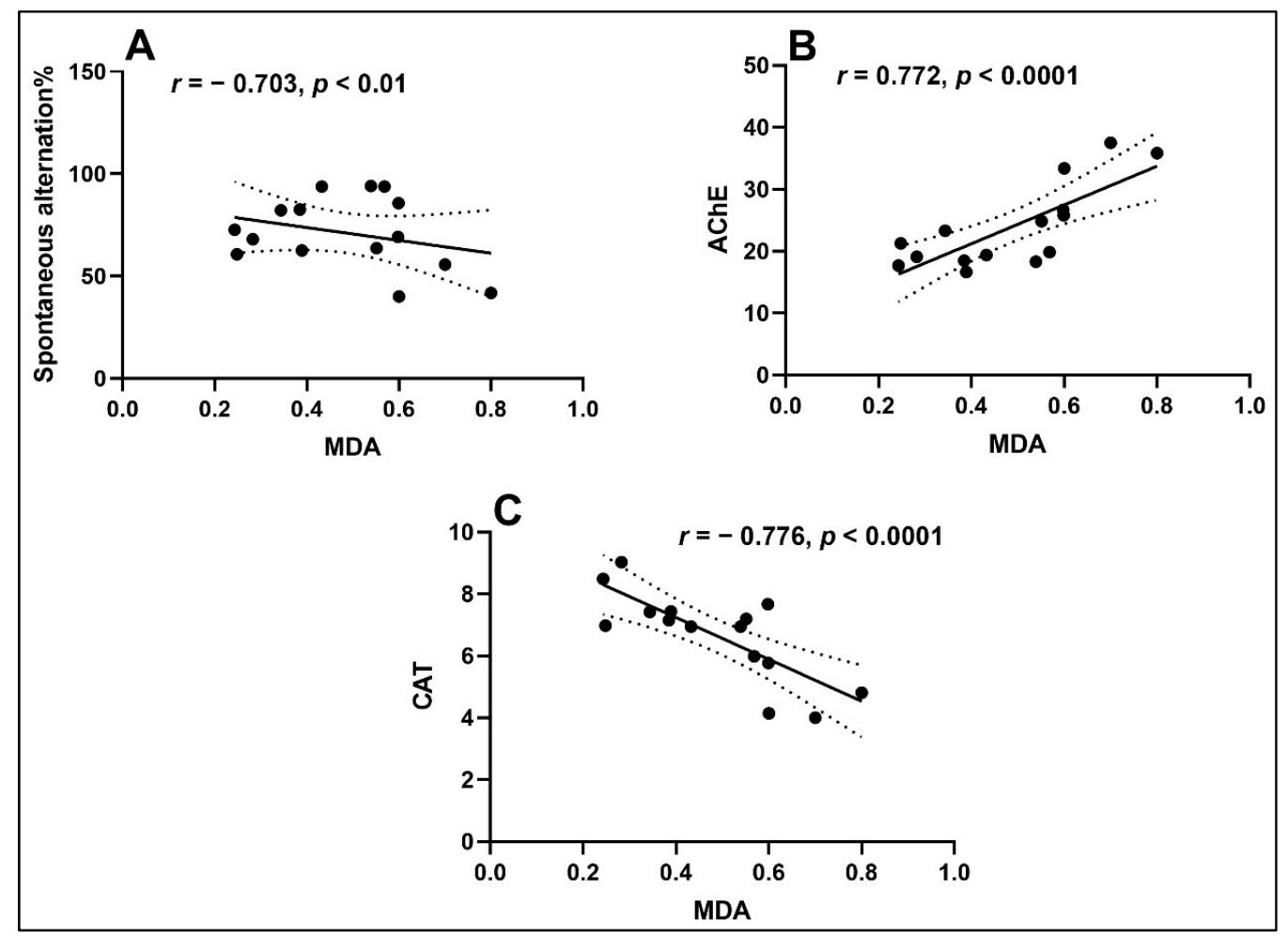

Figure 6. Statistical Pearson's correlation analyses of behavioral scores and oxidative stress markers $(n=5)$. Values expressed are spontaneous alternation $\%, \mathrm{AChE}(\mathrm{nmol} / \mathrm{min} / \mathrm{mg}$ protein), CAT (U/mg protein), and MDA (nmol/mg protein). (A) Spontaneous alternation $\%$ vs. MDA $(n=5, r=-0.703$, $p<0.01)$; (B) AChE vs. MDA $(n=5, r=0.772, p<0.0001)$; (C) CAT vs. MDA $(n=5, r=-0.776$, $p<0.0001)$.

\section{Conclusions}

In short, BL exposure may improve memory formation. At the same time, it can effectively diminish the cognitive deficits induced by Sco in the rat brain. The mechanism of the observed effects can be explained by decreasing in the AChE activity followed by increased level of antioxidant enzymes changed as a consequence of Sco administration. These new findings provide pharmacological and biochemical support for the development of the potential of BL in cognitive deficits.

Author Contributions: Conceptualization, I.E.O., and L.H.; methodology, I.B., R.S.B., and O.C.; software, I.B., R.S.B., and O.C.; formal analysis, I.B., R.S.B., and O.C.; investigation, I.B., R.S.B., and L.H.; resources, L.H., M.H., and I.E.O.; writing—original draft preparation, L.H., I.E.O., and O.C.; writing-review and editing, L.H., I.E.O., M.H. and O.C.; supervision, L.H.; funding acquisition, I.E.O., M.H., and L.H. All authors have read and agreed to the published version of the manuscript. 
Funding: The article processing charge was funded by Alexandru Ioan Cuza University of Iasi, Romania.

Institutional Review Board Statement: All experimental procedures were strictly conducted by the Directive 2010/63/EU of the European Parliament and of the Council of 22 September 2010 on the protection of animals with approval from the Ethical Committee (No. 15309/22.07.2019).

Informed Consent Statement: Not applicable.

Data Availability Statement: The data presented in this study are available on request from the corresponding author.

Conflicts of Interest: The authors declare no conflict of interest.

\section{References}

1. Zhou, J.; Yang, W.; Suo, D.; Li, Y.; Peng, L.; Xu, L.; Zeng, K.; Ren, T.; Wang, Y.; Zhou, Y.; et al. Moringa oleifera Seed Extract Alleviates Scopolamine-Induced Learning and Memory Impairment in Mice. Front. Pharmacol. 2018, 9, 389. [CrossRef] [PubMed]

2. Ferreira-Vieira, T.H.; Guimaraes, I.M.; Silva, F.R.; Ribeiro, F.M. Alzheimer's disease: Targeting the Cholinergic System. Curr. Neuropharmacol. 2016, 14, 101-115. [CrossRef] [PubMed]

3. Drever, B.D.; Anderson, W.G.L.L.; Johnson, H.; O'Callaghan, M.; Seo, S.; Choi, D.-Y.D.Y.; Riedel, G.; Platt, B. Memantine acts as a cholinergic stimulant in the mouse hippocampus. J. Alzheimer's Dis. 2007, 12, 319-333. [CrossRef]

4. Hansen, R.A.; Gartlehner, G.; Webb, A.P.; Morgan, L.C.; Moore, C.G.; Jonas, D.E. Efficacy and safety of donepezil, galantamine, and rivastigmine for the treatment of Alzheimer's disease: A systematic review and meta-analysis. Clin. Interv. Aging 2008, 3 , 211-225.

5. Lanctôt, K.L.; Rajaram, R.D.; Herrmann, N. Therapy for Alzheimer's disease: How effective are current treatments? Ther. Adv. Neurol. Disord. 2009, 2, 163-180. [CrossRef]

6. Lahiri, D.; Farlow, M.; Sambamurti, K.; Greig, N.; Giacobini, E.; Schneider, L. A Critical Analysis of New Molecular Targets and Strategies for Drug Developments in Alzheimers Disease. Curr. Drug Targets 2003, 4, 97-112. [CrossRef]

7. Pakala, R.S.; Brown, K.N. Cholinergic medications. 2020, pp. 1-6. Available online: https://www.statpearls.com/articlelibrary/ viewarticle/19472/ (accessed on 12 January 2021).

8. Bajo, R.; Pusil, S.; López, M.E.; Canuet, L.; Pereda, E.; Osipova, D.; Maestú, F.; Pekkonen, E. Scopolamine effects on functional brain connectivity: A pharmacological model of Alzheimer's disease. Sci. Rep. 2015, 5, 9748. [CrossRef]

9. Spinks, A.; Wasiak, J. Scopolamine (hyoscine) for preventing and treating motion sickness. Cochrane Database Syst. Rev. 2011. [CrossRef]

10. Ramos Reis, P.M.; Eckhardt, H.; Denise, P.; Bodem, F.; Lochmann, M. Localization of scopolamine induced electrocortical brain activity changes, in healthy humans at rest. J. Clin. Pharmacol. 2013, 53, 619-625. [CrossRef] [PubMed]

11. Wang, Y.; Gao, S.; Zheng, V.; Chen, L.; Ma, M.; Shen, S.; Qu, J.; Zhang, H.; Gurney, M.E.; O’Donnell, J.M.; et al. A novel PDE4D inhibitor BPN14770 reverses scopolamine-induced cognitive deficits via cAMP/SIRT1/Akt/Bcl-2 pathway. Front. Cell Dev. Biol. 2020, 8, 1531. [CrossRef]

12. Umukoro, S.; Okoh, L.; Igweze, S.C.; Ajayi, A.M.; Ben-Azu, B. Protective effect of Cyperus esculentus (tiger nut) extract against scopolamine-induced memory loss and oxidative stress in mouse brain. Drug Metab. Pers. Ther. 2020, 35. [CrossRef]

13. Lv, J.; Lu, C.; Jiang, N.; Wang, H.; Huang, H.; Chen, Y.; Li, Y.; Liu, X. Protective effect of ginsenoside Rh2 on scopolamine-induced memory deficits through regulation of cholinergic transmission, oxidative stress and the ERK-CREB-BDNF signaling pathway. Phyther. Res. 2021, 35, 337-345. [CrossRef] [PubMed]

14. Corpuz, H.M.; Fujii, H.; Nakamura, S.; Katayama, S. Fermented rice peptides attenuate scopolamine-induced memory impairment in mice by regulating neurotrophic signaling pathways in the hippocampus. Brain Res. 2019, 1720, 146322. [CrossRef] [PubMed]

15. Saura, C.A.; Valero, J. The role of CREB signaling in Alzheimer's disease and other cognitive disorders. Rev. Neurosci. 2011, 22, 153-169. [CrossRef] [PubMed]

16. Klinkenberg, I.; Blokland, A. The validity of scopolamine as a pharmacological model for cognitive impairment: A review of animal behavioral studies. Neurosci. Biobehav. R 2010, 34, 1307-1350. [CrossRef] [PubMed]

17. Stefanova, G.; Girova, T.; Gochev, V.; Stoyanova, M.; Petkova, Z.; Stoyanova, A.; Zheljazkov, V.D. Comparative study on the chemical composition of laurel (Laurus nobilis L.) leaves from Greece and Georgia and the antibacterial activity of their essential oil. Heliyon 2020, 6, e05491. [CrossRef] [PubMed]

18. Parthasarathy, V.; Zachariah, J.; Chempakam, B. Bay leaf. In Chemistry of Spices; Parthasarathy, V., Chempakam, B., John Zachariah, T., Eds.; CAB International: London, UK, 2008; pp. 435-455.

19. Vassileva, S.; Darlenski, R. Bay Leaf Phytodermatitis. Contact Dermatitis 2020. [CrossRef]

20. Popovic, M.; Kaurinovic, B.; Cebovic, T.; Vojinovic-Miloradov, M. 239 Effects of laurel (Laurus nobilis L.) leaves and berries ether oil, PCBs and CCl4 on production of oxygen radicals. Toxicol. Lett. 2003, 144, s67. [CrossRef]

21. Caputo, L.; Nazzaro, F.; Souza, L.; Aliberti, L.; De Martino, L.; Fratianni, F.; Coppola, R.; De Feo, V. Laurus nobilis: Composition of Essential Oil and Its Biological Activities. Molecules 2017, 22, 930. [CrossRef]

22. Nabila, B.; Piras, A.; Fouzia, B.; Falconieri, D.; Kheira, G.; Fedoul, F.-F.; Majda, S.-R. Chemical composition and antibacterial activity of the essential oil of Laurus nobilis leaves. Nat. Prod. Res. 2020, 1-5. [CrossRef] 
23. Porres-Martínez, M.; González-Burgos, E.; Carretero, M.E.; Gómez-Serranillos, M.P. Major selected monoterpenes -pinene and 1,8-cineole found in Salvia lavandulifolia (Spanish sage) essential oil as regulators of cellular redox balance. Pharm. Biol. 2015, 53, 921-929. [CrossRef]

24. Rodenak-Kladniew, B.; Castro, M.A.; Crespo, R.; Galle, M.; García de Bravo, M. Anti-cancer mechanisms of linalool and 1,8-cineole in non-small cell lung cancer A549 cells. Heliyon 2020, 6. [CrossRef]

25. Kim, K.; Bu, Y.; Jeong, S.; Lim, J.; Kwon, Y.; Cha, D.S.; Kim, J.; Jeon, S.; Eun, J.; Jeon, H. Memory-enhancing effect of a supercritical carbon dioxide fluid extract of the needles of Abies koreana on scopolamine-induced amnesia in mice. Biosci. Biotechnol. Biochem. 2006, 70, 1821-1826. [CrossRef]

26. Bate, S.T.; Clark, R.A. The Design and Statistical Analysis of Animal Experiments; Cambridge University Press: Cambridge, UK, 2014; ISBN 9781139344319.

27. Boiangiu, R.S.; Brinza, I.; Hancianu, M.; Erdogan Orhan, I.; Eren, G.; Gündüz, E.; Ertas, H.; Hritcu, L.; Cioanca, O. Cognitive Facilitation and Antioxidant Effects of an Essential Oil Mix on Scopolamine-Induced Amnesia in Rats: Molecular Modeling of In Vitro and In Vivo Approaches. Molecules 2020, 25, 1519. [CrossRef]

28. Merali, Z.; Cayer, C.; Kent, P.; Liu, R.; Cal, V.; Harris, C.S.; Arnason, J.T. Sacred Maya incense, copal (Protium copal - Burseraceae), has antianxiety effects in animal models. J. Ethnopharmacol. 2018, 216, 63-70. [CrossRef]

29. Jackson, L.L. VTE on an elevated T-maze. J. Comp. Psychol. 1943, 36, 99-107. [CrossRef]

30. Olton, D.S.; Samuelson, R.J. Remembrance of places passed: Spatial memory in rats. J. Exp. Psychol. Anim. B. 1976, 2, 97-116. [CrossRef]

31. Haider, S.; Liaquat, L.; Ahmad, S.; Batool, Z.; Siddiqui, R.A.; Tabassum, S.; Shahzad, S.; Rafiq, S.; Naz, N. Naringenin protects $\mathrm{AlCl} 3 / \mathrm{D}$-galactose induced neurotoxicity in rat model of $\mathrm{AD}$ via attenuation of acetylcholinesterase levels and inhibition of oxidative stress. PLoS ONE 2020, 15, e0227631. [CrossRef]

32. Foyet, H.S.; Asongalem, A.E.; Oben, E.K.; Cioanca, O.; Hancianu, M.; Hritcu, L. Effects of the Methanolic Extract of Vitellaria paradoxa Stem Bark Against Scopolamine-Induced Cognitive Dysfunction and Oxidative Stress in the Rat Hippocampus. Cell. Mol. Neurobiol. 2016, 36, 1139-1149. [CrossRef] [PubMed]

33. Ellman, G.; Courtney, K.; Andres, V.J.; Feather-Stone, R. A new and rapid colorimetric determination of acetylcholinesterase activity. Biochem. Pharmacol. 1961, 7, 88-95. [CrossRef]

34. Winterbourn, C.; Hawkins, R.; Brian, M.; Carrell, R. The estimation of red cell superoxide dismutase activity. J. Lab Clin. Med. $1975,85,337$.

35. Sinha, A.K. Colorimetric assay of catalase. Anal. Biochem. 1972, 47, 389-394. [CrossRef]

36. Oliver, C.N.; Ahn, B.W.; Moerman, E.J.; Goldstein, S.; Stadtman, E.R. Age-related changes in oxidized proteins. J. Biol. Chem. 1987, 262, 5488-5491. [CrossRef]

37. Luo, S.; Wehr, N.B. Protein carbonylation: Avoiding pitfalls in the 2,4-dinitrophenylhydrazine assay. Redox Rep. 2009, 14, 159-166. [CrossRef] [PubMed]

38. Ohkawa, H.; Ohishi, N.; Yagi, K. Assay for lipid peroxides in animal tissues by thiobarbituric acid reaction. Anal Biochem 1979, 95, 351-358. [CrossRef]

39. Smith, P.K.; Krohn, R.I.; Hermanson, G.T.; Mallia, A.K.; Gartner, F.H.; Provenzano, M.D.; Fujimoto, E.K.; Goeke, N.M.; Olson, B.J.; Klenk, D.C. Measurement of protein using bicinchoninic acid. Anal. Biochem. 1985, 150, 76-85. [CrossRef]

40. Olejnik, A.; Sliwowska, A.; Nowak, I. Jasmonic acid, methyl jasmonate and methyl dihydrojasmonate as active compounds of topical formulations. Colloids Surf. A Physicochem. Eng. Asp. 2018, 558, 558-569. [CrossRef]

41. Lahlou, M. Essential oils and fragrance compounds: Bioactivity and mechanisms of action. Flavour Fragr. J. 2004, 19, 159-165. [CrossRef]

42. Can Başer, K.H.; Buchbauer, G. Handbook of Essential Oils: Science, Technology, and Applications, 2nd ed.; CRC Press Taylor \& Francis Group: New York, NY, USA, 2015; ISBN 9781466590472.

43. Adorjan, B.; Buchbauer, G. Biological properties of essential oils: An updated review. Flavour Fragr. J. 2010, 25, 407-426. [CrossRef]

44. Našel, C.; Našel, B.; Samec, P.; Schindler, E.; Buchbauer, G. Functional imaging of effects of fragrances on the human brain after prolonged inhalation. Chem. Senses 1994, 19, 359-364. [CrossRef]

45. Dammak, I.; Hamdi, Z.; Kammoun El Euch, S.; Zemni, H.; Mliki, A.; Hassouna, M.; Lasram, S. Evaluation of antifungal and anti-ochratoxigenic activities of Salvia officinalis, Lavandula dentata and Laurus nobilis essential oils and a major monoterpene constituent 1,8-cineole against Aspergillus carbonarius. Ind. Crops Prod. 2019, 128, 85-93. [CrossRef]

46. Taban, A.; Saharkhiz, M.J.; Niakousari, M. Sweet bay (Laurus nobilis L.) essential oil and its chemical composition, antioxidant activity and leaf micromorphology under different extraction methods. Sustain. Chem. Pharm. 2018, 9, 12-18. [CrossRef]

47. Peixoto, L.R.; Rosalen, P.L.; Ferreira, G.L.S.; Freires, I.A.; de Carvalho, F.G.; Castellano, L.R.; de Castro, R.D. Antifungal activity, mode of action and anti-biofilm effects of Laurus nobilis Linnaeus essential oil against Candida spp. Arch. Oral Biol. 2017, 73, 179-185. [CrossRef] [PubMed]

48. Al-Kalaldeh, J.Z.; Abu-Dahab, R.; Afifi, F.U. Volatile oil composition and antiproliferative activity of Laurus nobilis, Origanum syriacum, Origanum vulgare, and Salvia triloba against human breast adenocarcinoma cells. Nutr. Res. 2010, 30, 271-278. [CrossRef]

49. Pacifico, S.; Gallicchio, M.; Lorenz, P.; Duckstein, S.M.; Potenza, N.; Galasso, S.; Marciano, S.; Fiorentino, A.; Stintzing, F.C.; Monaco, P. Neuroprotective Potential of Laurus nobilis Antioxidant Polyphenol-Enriched Leaf Extracts. Chem. Res. Toxicol. 2014, 27, 611-626. [CrossRef] 
50. CHO, E.-Y.; LEE, S.-J.; NAM, K.-W.; SHIN, J.; OH, K.; KIM, K.H.; MAR, W. Amelioration of Oxygen and Glucose DeprivationInduced Neuronal Death by Chloroform Fraction of Bay Leaves (Laurus nobilis). Biosci. Biotechnol. Biochem. 2010, 74, $2029-2035$. [CrossRef] [PubMed]

51. Pacifico, S.; Gallicchio, M.; Lorenz, P.; Potenza, N.; Galasso, S.; Marciano, S.; Fiorentino, A.; Stintzing, F.C.; Monaco, P. Apolar Laurus nobilis leaf extracts induce cytotoxicity and apoptosis towards three nervous system cell lines. Food Chem. Toxicol. 2013, 62, 628-637. [CrossRef] [PubMed]

52. Lee, G.Y.; Lee, C.; Park, G.H.; Jang, J.H. Amelioration of Scopolamine-Induced Learning and Memory Impairment by $\alpha$-Pinene in C57BL/ 6 Mice. Evid. Based Complement. Altern. Med. 2017, 2017, 4926815. [CrossRef]

53. Goto, S.; Suzuki, H.; Nakagawa, T.; Shimizu, K. The Effect of Eucalyptol on Nursing Home Residents. Sci. Rep. 2020, 10, 3996. [CrossRef] [PubMed]

54. Gomes, P.B.; Feitosa, M.L.; Silva, M.I.G.; Noronha, E.C.; Moura, B.A.; Venâncio, E.T.; Rios, E.R.V.; de Sousa, D.P.; de Vasconcelos, S.M.M.; Fonteles, M.M.d.F.; et al. Anxiolytic-like effect of the monoterpene 1,4-cineole in mice. Pharmacol. Biochem. Behav. 2010, 96, 287-293. [CrossRef] [PubMed]

55. Pavan, B.; Dalpiaz, A. Odorants could elicit repair processes in melanized neuronal and skin cells. Neural Regen. Res. 2017, 12, 1401. [CrossRef] [PubMed]

56. Taslimi, P.; Gulçin, İ. Antioxidant and anticholinergic properties of olivetol. J. Food Biochem. 2018, 42, e12516. [CrossRef]

57. Dunant, Y.; Gisiger, V. Ultrafast and Slow Cholinergic Transmission. Different Involvement of Acetylcholinesterase Molecular Forms. Molecules 2017, 22, 1300. [CrossRef] [PubMed]

58. Kowalczyk, J.; Kurach, Ł.; Boguszewska-Czubara, A.; Skalicka-Woźniak, K.; Kruk-Słomka, M.; Kurzepa, J.; Wydrzynska-Kuźma, M.; Biała, G.; Skiba, A.; Budzyńska, B. Bergapten Improves Scopolamine-Induced Memory Impairment in Mice via Cholinergic and Antioxidative Mechanisms. Front. Neurosci. 2020, 14. [CrossRef] [PubMed]

59. Deng, G.; Wu, C.; Rong, X.; Li, S.; Ju, Z.; Wang, Y.; Ma, C.; Ding, W.; Guan, H.; Cheng, X.; et al. Ameliorative effect of deoxyvasicine on scopolamine-induced cognitive dysfunction by restoration of cholinergic function in mice. Phytomedicine 2019, 63, 153007. [CrossRef]

60. Gazwi, H.S.S.; Yassien, E.E.; Hassan, H.M. Mitigation of lead neurotoxicity by the ethanolic extract of Laurus leaf in rats. Ecotoxicol. Environ. Saf. 2020, 192, 110297. [CrossRef]

61. Ferreira, A.; Proença, C.; Serralheiro, M.L.M.; Araújo, M.E.M. The in vitro screening for acetylcholinesterase inhibition and antioxidant activity of medicinal plants from Portugal. J. Ethnopharmacol. 2006, 108, 31-37. [CrossRef]

62. Wang, X.-C.; Xu, Y.-M.; Li, H.-Y.; Wu, C.-Y.; Xu, T.-T.; Luo, N.-C.; Zhang, S.-J.; Wang, Q.; Quan, S.-J. Jiao-Tai-Wan Improves Cognitive Dysfunctions through Cholinergic Pathway in Scopolamine-Treated Mice. Biomed Res. Int. 2018, 2018, 1-16. [CrossRef]

63. Uma, G.; Uma Maheswari, S. Neuroprotective effects of polyherbal formulation (Indian NONI) on scopolamine-induced memory impairment in mice. Int. J. Pharm. Pharm. Sci. 2014, 6, 354-357.

64. Capatina, L.; Todirascu-Ciornea, E.; Napoli, E.M.; Ruberto, G.; Hritcu, L.; Dumitru, G. Thymus vulgaris Essential Oil Protects Zebrafish against Cognitive Dysfunction by Regulating Cholinergic and Antioxidants Systems. Antioxidants 2020, 9, 1083. [CrossRef]

65. Abd-El-Fattah, M.A.; Abdelakader, N.F.; Zaki, H.F. Pyrrolidine dithiocarbamate protects against scopolamine-induced cognitive impairment in rats. Eur. J. Pharmacol. 2014, 723, 330-338. [CrossRef] [PubMed]

66. Türkez, H.; Toğar, B. Aluminum phosphide-induced genetic and oxidative damages in rats: Attenuation by Laurus nobilis leaf extract. Toxicol. Ind. Health 2013, 29, 579-583. [CrossRef] [PubMed]

67. Ham, A.; Kim, B.; Koo, U.; Nam, K.-W.; Lee, S.-J.; Kim, K.H.; Shin, J.; Mar, W. Spirafolide from bay leaf (Laurus nobilis) prevents dopamine-induced apoptosis by decreasing reactive oxygen species production in human neuroblastoma SH-SY5Y cells. Arch. Pharm. Res. 2010, 33, 1953-1958. [CrossRef] [PubMed] 